\title{
Services Science Journey: Foundations, Progress, and Challenges
}

\author{
Mary Jo Bitner \\ PetSmart Chair in Services Leadership \\ Stephen W. Brown \\ Edward Carson Chair in Services Marketing \\ Michael Goul \\ Professor of Information Systems \\ Susan Urban \\ Professor of Computer Science and \\ Engineering
}

\author{
Arizona State University \\ Tempe, Arizona \\ Contact: \\ maryjo.bitner@asu.edu \\ 480-965-6201
}

\begin{abstract}
A B S T R A C T
With the explosive growth of services in economies worldwide comes the growing recognition of a need for trans-disciplinary research, new business models, and innovative degree programs to propel innovation in services. This paper paints a picture of the history as well as new initiatives at Arizona State University that are aimed at addressing these needs. Building on over twenty years of research that is anchored in ASU's Center for Services Leadership in the W. P. Carey School of Business, we are currently embarking on a Services Science Initiative to enlarge our successes beyond the business disciplines and to engage a broader academic community. This paper shares our current vision of where we are headed as well as some of the challenges to overcome and resources needed to move forward. Authored by senior faculty across several disciplines, this paper symbolizes our conviction that cross-disciplinary efforts of this magnitude require the energy and commitment of senior faculty as well as partnerships with business and government.
\end{abstract}

\section{The Services Science Journey Begins}

The explosive growth of services in economies around the world has vast implications for business practice, academic knowledge creation, education, and government policy. Led by the visionary efforts of IBM, the academic pioneers, and some governments and governmental entities, there is a growing awareness of these implications and the need to focus on services innovation. For example, the Office for Economic Cooperation and Development (OECD) recently released a report in which it noted that government policy in developed countries has not been attuned to the service sector [1]. Along with the awareness of the need for service innovation, has come the discovery that research in service innovation requires cross-disciplinary work. 
While the ultimate outcome is still unclear, this focus on service innovation may lead to the formation of a new discipline (e.g., "services science" or "services science, management and engineering"), or at the very least to greater cross-disciplinary collaboration to address educational as well as knowledge development needs. Failure to innovate effectively in services could doom individual companies in their efforts to compete and whole economies in their efforts to grow. The result of failure would be reduced opportunities and quality of life for individuals.

Within the business disciplines, Arizona State University (ASU), through its Center for Services Leadership, has been a leader for over twenty years in developing knowledge and educational programs for services management and marketing. To this end, we have led trans-disciplinary research across the business disciplines of operations, marketing, and human resources and with leading private sector, for-profit businesses. Today, we are embarked on a journey to replicate and enlarge these successes by expanding the scope of services leadership to become even more cross disciplinary-spanning the social sciences, engineering, and computer science-within our own institution and with alliance partners. Beyond the academic disciplines, we also envision greater involvement of governments, industry associations, private foundations, and non-profit entities to support service innovation research and education

This paper paints the picture of where we are on this journey, the challenges we and others will face, and some of the things we envision could be possible. It concludes with the type of help we believe is needed from government and the private sector if we are to keep moving forward. Note that this paper is coauthored by senior faculty from multiple disciplines. While it isn't easy, we firmly believe that this type of cooperation and leadership will be essential to move services science forward.

\section{A Working Definition of Services Science}

To facilitate our work, we have adopted the following working definition of services science:

Services Science is an emerging discipline that focuses on fundamental science, models, theories and applications to drive innovation, competition, and quality of life through service(s).

This definition suggests a focus on substantive outcomes (innovation, competition, and quality of life), grounded in rigorous research (science, models, theories and applications). The definition does not preclude any relevant discipline from participating, nor does it prescribe a particular type of research methodology. 


\section{Services Leadership Traditions in Business Schools and at ASU}

There is a long tradition of services management and marketing research within business schools [2]. This work has focused on theory-based, yet practical issues of helping individual firms to be more competitive through focusing on service(s). Since the 1980s, models, frameworks, and empirical work have supported this focus. Since much of the work has emanated from the marketing discipline, there is a very strong customer-centric flavor to the research. There is much to be learned from this rich tradition and body of work that boasts contributions from academics around the world, is rooted in real issues of business, and spans multiple business disciplines.

At ASU, our services leadership efforts historically have been focused within the Center for Services Leadership (CSL) in the W. P. Carey School of Business. ${ }^{1}$ Working with over forty leading businesses (including IBM, Marriott International, Hewlett-Packard, Charles Schwab, Southwest Airlines, Mayo Clinic, SAP and others), the CSL provides executive education and research to further science and services leadership in companies. The CSL's research faculty have published in the leading business journals, written a prominent services textbook used worldwide, and have received many national and international awards for their work in services science. The CSL also supports and provides guidance for our academic courses, degree programs, and student internships and projects in services leadership.

\section{Services Science Initiative AT ASU}

Currently, we are developing the next generation of services leadership for our campus. We are working across disciplines on a "Services Science Initiative" that will provide an umbrella for bringing together much of what is currently being done within the broad definition of services science on our campus. Ideally, the Initiative will also provide a forum and energy for new projects, degree programs, and funding. Faculty from the W. P. Carey School of Business, the Fulton School of Engineering, the School of Computing and Informatics, and the Prevention Research Center in Psychology are involved. In addition, the Initiative will provide a hub for inter-university alliances and business partnerships in services science.

Anchored in the CSL, the disciplines that are leading the Services Science Initiative are: services leadership, marketing, information systems, and computer science and informatics. We have also involved individual faculty from supply chain, health care, and psychology and envision including additional faculty from design, architecture and anthropology as we expand.

1 www.wpcarey.asu.edu/csl 


\section{Research Clusters}

One of the challenges of cross-disciplinary research is how to motivate faculty and researchers to work across disciplines. The inherent semantic challenges, as well as incongruent incentive structures are barriers that keep many researchers from participating. It is hard work, and the rewards are not always clear. This is particularly true for younger faculty who are necessarily wedded to the promotion and reward structures of their disciplines. Dual appointments and shared rewards are partial answers.

Another complementary approach that we will use is to bring groups of faculty together around real-world, significant challenges that require investigators with different disciplinary backgrounds to learn enough about each other's perspectives (conceptually, methodologically and substantively) to work together to study and tackle those problems by relying on merged perspectives informed by the range of their disciplines. By identifying key challenges and organizing research clusters of faculty who are interested in applying their knowledge to solving these challenges, we hope to motivate the type of crossdisciplinary research collaboration needed to solve the problems, many of which have global implications. This type of collaboration can spawn innovative solutions that could have real impact on real problems.

Some of the research clusters we foresee developing within our Services Science Initiative include groups that would focus on: IT Services Solutions; Business Models for Services; Computing Models for Services; Healthcare Innovation; Technology and Service Delivery; Service Design; Customer Loyalty and Relationships. We already have individual faculty, and in some cases cross-disciplinary groups, working in all of these areas. We have begun to identify broader representations of faculty and industry partners within each of these challenge areas.

\section{Services Science Degree Programs}

There are a number of existing and proposed cross-disciplinary degree programs and specializations at ASU that fall within the broad definition of services science including:

- MBA Specialization in Strategic Marketing and Services Leadership (for over ten years)

- Shanghai MBA in Services Management (for Chinese executives, through the W. P. Carey School, beginning 2007)

- Technology, Science and Engineering MBA degree (for technology companies, offered through W. P. Carey School and Fulton School of Engineering)

- Undergraduate Dual Degree in Business and Engineering (proposed)

- Ph.D. Seminar in Services Leadership (in W. P. Carey School with anticipated crosscampus enrollment, beginning 2006) 
In addition, a trans-disciplinary research effort known as Collaborative Enterprise Services Ecosystems (CESE) has been established, integrating research and education in computer science, industrial engineering, information systems, and services leadership in the study of the dynamic and self-adjusting behavior required for computing support of businessto-business and business-to-customer collaboration in a service-oriented environment. The CESE hopes to establish an interdisciplinary Ph.D. program with industry participation and support.

\section{Executive Education in Services}

In addition to formal degree programs for students, ASU offers a number of avenues for executive education in services leadership including two flagship annual programs: The Compete Through Service Symposium in November (annual for sixteen years), and the Services Leadership Institute in March (annual for twenty years). In addition, customized programs in services leadership and supply chain management are provided for individual companies.

\section{Partnerships and Alliances}

To be truly successful, we believe our Services Science Initiative must reach beyond our own limitations and academic borders to form alliances with private business, governments, and other universities.

Through the CSL we already have strong relationships with over forty business partners and a board of advisors made up of senior executives representing leading manufacturing and service companies. Each of these business partners recognizes the critical importance of services to their ability to innovate and compete in the future. We envision gradually expanding the number of partnerships as well as involving partners with faculty research clusters.

Beyond private business, we have alliances with individual services faculty and universities around the globe who have centers for services research and education. Most of these services science alliances are currently with business schools and business faculty. We envision expanding to include alliances with groups in the design sciences, computer science, and information systems.

\section{Challenges for Developing a Crossdisciplinary Initiative}

There is strong support at our university and many others for cross-disciplinary research and education programs. For example, ASU's President, Michael Crow, has made transdisciplinary research and education a central platform of his vision for the "New American University." Over the past four years more than ten trans-disciplinary institutes or schools 
have been established including the International Institute for Sustainability, the School of Global Studies, The Biodesign Institute, the Institute for Computing and Information Science and Engineering, and the new School of Computing and Informatics. Some universities, like the University of Wisconsin at Madison, have placed paramount importance on trans-disciplinary work for a long time, while many others at least give it lip service.

Yet, there are many challenges and hurdles to overcome that sometimes get in the way of trans-disciplinary initiatives. Among those are inconsistencies in reward and incentive structures as noted earlier. We have become aware of this particular challenge as we combine efforts across business and engineering schools. While business faculty are asked more and more to generate revenue through research grants and other means, the tenure and promotion process in most business schools, including our own, is based to a large degree on publication of articles in premier journals. On the other hand, our engineering colleagues are strongly incented to raise dollars through large government grants and private funding, in addition to generating journal publications. These inconsistencies, while not insurmountable by any means, need to be acknowledged and dealt with in order for trans-disciplinary research partnerships to be successful.

Another big challenge is related to semantics. Each discipline has its own peculiar language. Often researchers in different disciplines find they are talking about the same thing but using different terms. While it may seem relatively inconsequential, these types of semantic and definitional discussions can sidetrack, or at least significantly slow, collaborative research progress.

Finally, there are funding and resource challenges. Trans-disciplinary efforts require funding across disciplines, yet traditional sources of funding tend to be discipline-specific. Thus, it is difficult to know where to look for funding of cross-disciplinary initiatives, and the outcome of proposals is uncertain. Further, to date there are few clearly identifiable sources of funding for services research, education, and innovation. Much of the research funding, particularly in the U.S., is tied to technology innovation and the hard sciences.

\section{How Can Government, Industry, and Foundations Help?}

There is significant enthusiasm and interest related to service innovation and services science building within the business and academic communities worldwide. We have shared insights with each other, published papers, held workshops, developed degree programs, and shared course syllabi and methods.

It appears we have reached a critical juncture where the enthusiasm and potential are high, and there is energy ready to move forward. To capitalize on the momentum, we need to find ways to significantly fund the next stages of services science. We need funding from government, private business, and foundations to catalyze these efforts and move them 
forward quickly. Other countries are doing this, and the U.S. should follow. Funding is needed for individual research programs as well as research enterprises and centers. Funding is needed to incentivize faculty and schools to become involved in cross-disciplinary research and educational offerings. Finally, funding is needed for advocacy work that will promote services science within governmental structures.

\section{References}

[1] Organization for Economic Cooperation and Development (2005), "Promoting Innovation in Services."

[2] Bitner, Mary Jo and Stephen W. Brown (2006), "The Evolution and Discovery of Services Science in Business Schools," Communications of the ACM, July, 73-78. 